\title{
A Rare Moment of Cross-Partisan Consensus: Elite and Public Response to the COVID-19 Pandemic in Canada
}

\author{
Eric Merkley \\ University of Toronto \\ eric.merkley@utoronto.ca \\ Peter John Loewen \\ University of Toronto \\ peter.loewen@utoronto.ca \\ Derek Ruths \\ McGill University \\ derek.ruths@mcgill.ca
}

\author{
Aengus Bridgman \\ McGill University \\ aengus.bridgman@mail.mcgill.ca \\ Taylor Owen \\ McGill University \\ taylor.owen@mcgill.ca \\ Oleg Zhilin \\ McGill University \\ oleg.zhilin@mail.mcgill.ca
}

Forthcoming in the Canadian Journal of Political Science

\begin{abstract}
The COVID-19 pandemic has placed nearly unprecedented pressure on policymakers and citizens alike. Effectively containing the pandemic requires a societal consensus. However, a long line of research in political science has told us that polarization tends to occur on highly salient topics because partisans "follow the leader." We examine the degree of partisan consensus that exists in Canada at the level of political elites and the mass public. We analyze Member of Parliament (MP) Twitter behaviour and show a massive increase in attention to COVID-19 and find no evidence of any MPs from any party downplaying the pandemic. We find no association between Conservative Party vote share and Google search interest in the coronavirus, while survey data show that individual-level partisan differences are small and disappear when controlling for demographics and left-right ideology. Elite and public response to the COVID-19 pandemic can be characterized as a cross-partisan consensus.
\end{abstract}


The COVID-19 pandemic requires an effort to coordinate the actions of government and society unmatched in recent history. Individual citizens need to voluntarily sacrifice economic and social activity for an indefinite period of time to protect others. At the same time, we know that public opinion tends to become polarized on highly salient issues, except when political elites are in consensus (Berinsky, 2009; Zaller, 1992). Avoiding elite and public polarization is thus essential for an effective societal response to the pandemic. In the United States, there appears to be elite and public polarization on the severity of the pandemic (Gadarian et al., 2020). Other evidence suggests that polarization is undermining compliance with social distancing (Cornelson \& Miloucheva, 2020). Using a multi-method approach, we show that Canadian political elites and the public are in a unique period of cross-partisan consensus on important questions related to the COVID-19 pandemic, such as its seriousness and the necessity of social distancing.

\section{Elite Cues and Public Opinion}

The theory that political elites have the power to shape public attitudes has a long history in political science. Citizens "follow the leader" in part as a low-information shortcut to form opinions likely to be in line with their interests (Mondak, 1993) or to reaffirm their deeply-rooted partisan identities (Bakker et al., 2019). Observational and experimental research has thus found public attitudes to be highly responsive to cues from parties (Berinsky, 2009; Lenz, 2012; Mondak, 1993), especially on novel, "hard" issues where citizens are dependent on the news media for information (Tesler, 2018; Zaller, 1992).

Polarization is often the norm on highly salient political issues, and this has been true for matters of science as well. For example, there is substantial evidence that divided political elites polarized American attitudes towards climate science (Carmichael \& Brulle, 2017; Merkley \& Stecula, 2020; Tesler, 2018). Polarization can only be avoided if elites send signals of consensus (Berinsky, 2009; Zaller, 1992). Most research on cue-taking has been situated in the United States, but some work has illustrated the importance of elite cues comparatively (Bischof \& Wagner, 2019), and in Canada specifically (Merolla et al., 2016).

The implications of elite disagreement on an issue like the COVID-19 pandemic are considerable. Divided parties send polarizing signals to the mass public that could undermine efforts to fight the virus. In the United States, Republican officials voiced skepticism about the severity of the pandemic early in the crisis and attitudes towards COVID-19 are heavily polarized, perhaps as a result (Gadarian et al., 2020). The past few decades have seen polarization increase in Canada (Cochrane, 2015). Here, we evaluate the degree to which the politics in Canada regarding COVID19 can be characterized by partisan polarization.

\section{Data and Methods}

We employ data from the social media accounts of federal Members of Parliament (MP), Google search trends, and public opinion surveys to evaluate the response to COVID-19. To assess elite cues, we collected all tweets from MPs who use Twitter (292 accounts with a total of 33,142 tweets since January 1, 2020). We used keyword searches to classify tweets into one or more topics. We 
calculate the share of MP tweets mentioning COVID-19 by party and benchmark these series against other issues (environment and immigration). Hand-coding was done on all tweets that related to COVID-19 to identify signals downplaying the severity of the crisis and messages promoting social distancing.

Following the elite cue analysis, we gauge the relationship between partisanship and concern about COVID-19 at both the aggregate and individual levels. We collected Google Search Trends for the search term "coronavirus" in the first half (1-14) and second half (15-31) of March. We average these two periods together at the municipal level $(\mathrm{N}=87)$. These data show the relative difference in search interest in the coronavirus between municipalities. We obtained municipal-level estimates of the Conservative Party's vote share, as well as population size (logged), population density (logged), average median income, and share of population with postsecondary education. ${ }^{1}$ We construct an urban index, with population size and density, and a socioeconomic status (SES) index, from education and income levels (both scaled 0-1). We estimate a model predicting relative search interest in the coronavirus with Conservative Party vote share, the urban and SES indices, and provincial fixed effects with robust standard errors.

We conducted a survey of 2,499 Canadian citizens 18 years and older from the online sample provider Dynata fielded from April 2-6. National level quotas were set on region (i.e. Atlantic, Quebec, Ontario, West), age, gender, and language. Data was weighted within each region of Canada by gender and age based on data from the 2016 Canadian census. We asked our respondents their level of concern with COVID-19, and how serious of a threat they believed it to be for themselves and for Canadians in general. We create a COVID-19 severity index from these responses, scaled from $0-1$.

We also asked our respondents whether or not they have engaged in a series of social distancing behaviours. We use principal components analysis to identify two dimensions that run through these responses, roughly corresponding to their offline (eg. avoiding large crowds) and online (eg. working from home) social distancing. Consequently, we construct two indices of social distancing from these factors scaled from 0-1. Factor loadings can be found in Table A1. We estimate models regressing our severity and social distancing indices on partisanship and left-right ideology, ${ }^{2}$ with controls for income, education, age, religiosity, urban residence, gender, French language, and region.

\footnotetext{
${ }^{1}$ The vote share estimates areal weighted interpolation to map 2015 polling-station-level results into census subdivision (i.e. municipal) boundaries. Municipal-level data was generously shared by Jack Lucas. Other municipal-level measures are publicly available at: https://dataverse.scholarsportal.info/dataset.xhtml?persistentId=doi:10.5683/SP2/947REI

${ }^{2}$ Measured as an index of 5 policy questions coded in a left-right direction, scaled from 0-1. Descriptive statistics and variable descriptions for aggregate and individual analyses can be found in Table S1 of the online supplement.
} 
- Conservative - Liberal - NDP
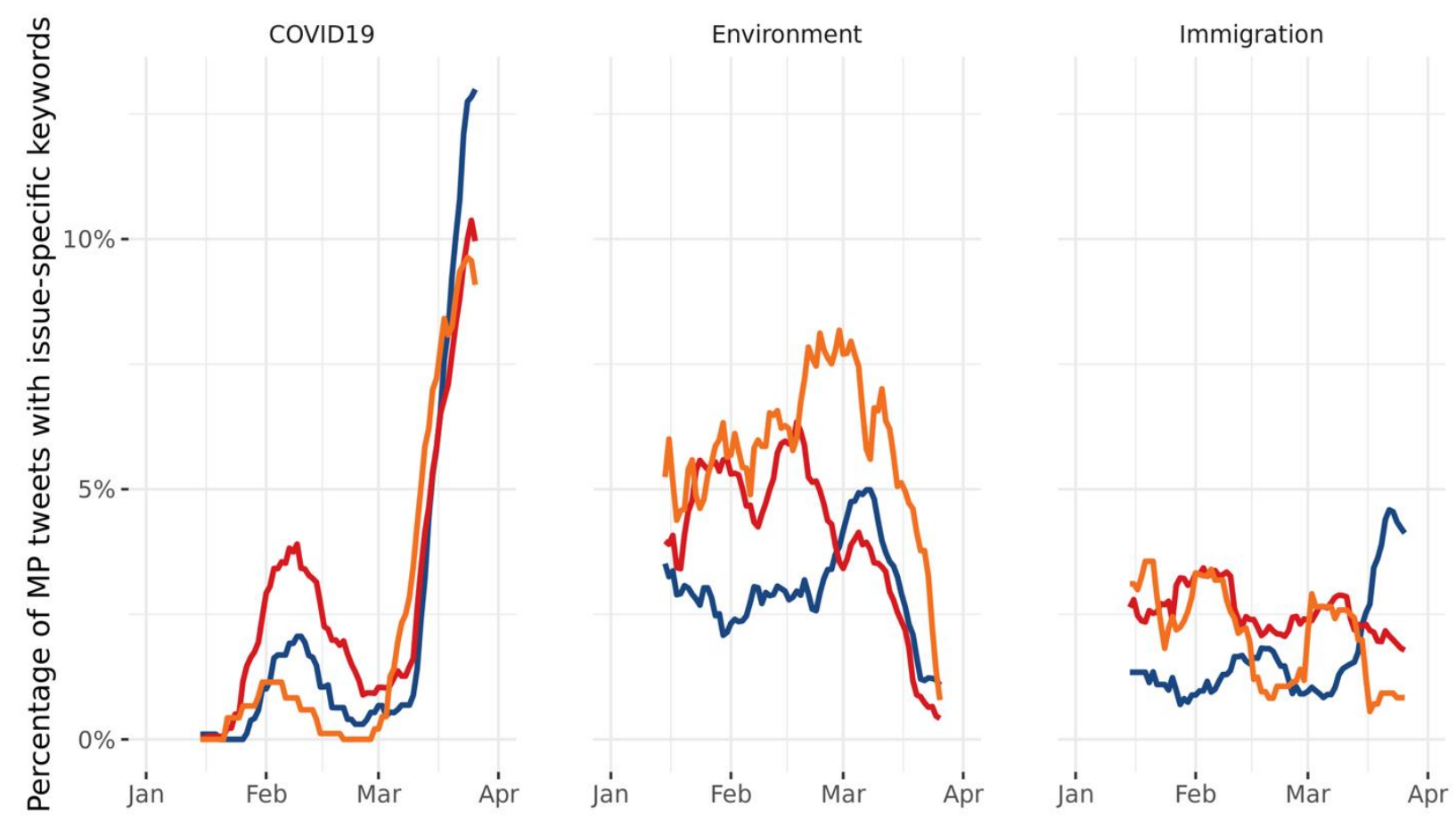

Figure 1. Rolling percentage $(n=15)$ of tweets focused on COVID19, the environment, and immigration from federal Members of Parliament as identified by keyword searches.

\section{Results}

Quantitative and qualitative reviews of MP tweets from January 1 to March 28 from the three national parties with official party status indicate that political elites in Canada have presented a united front on the nature and severity of the COVID-19 pandemic. Figure 1 shows relatively low focus on the virus until early March at which point discussion from all parties explodes, with tweets on other issues that have historically been important in the Canadian context seeing a sizable reduction. More information on the keywords for the automated analysis and Tweet frequency by party can be found in the online supplement.

Counts do not tell the whole story, however, and it may be that the increased attention is principally partisan. We thus qualitatively coded all tweets mentioning COVID19 in our sample (N $=1260$ ). Our coding indicated that members from all three parties heavily emphasized (in roughly equal proportions) the importance of social distancing measures and proper hygiene practices, like hand washing and not touching one's face. Additionally, there were zero tweets among MPs of any parties that indicated that concerns from COVID19 were overblown or exaggerated or that spread misinformation (e.g. vitamins, high temperatures, bats, no worse than the flu). Coding criteria can be found in the online supplement. 

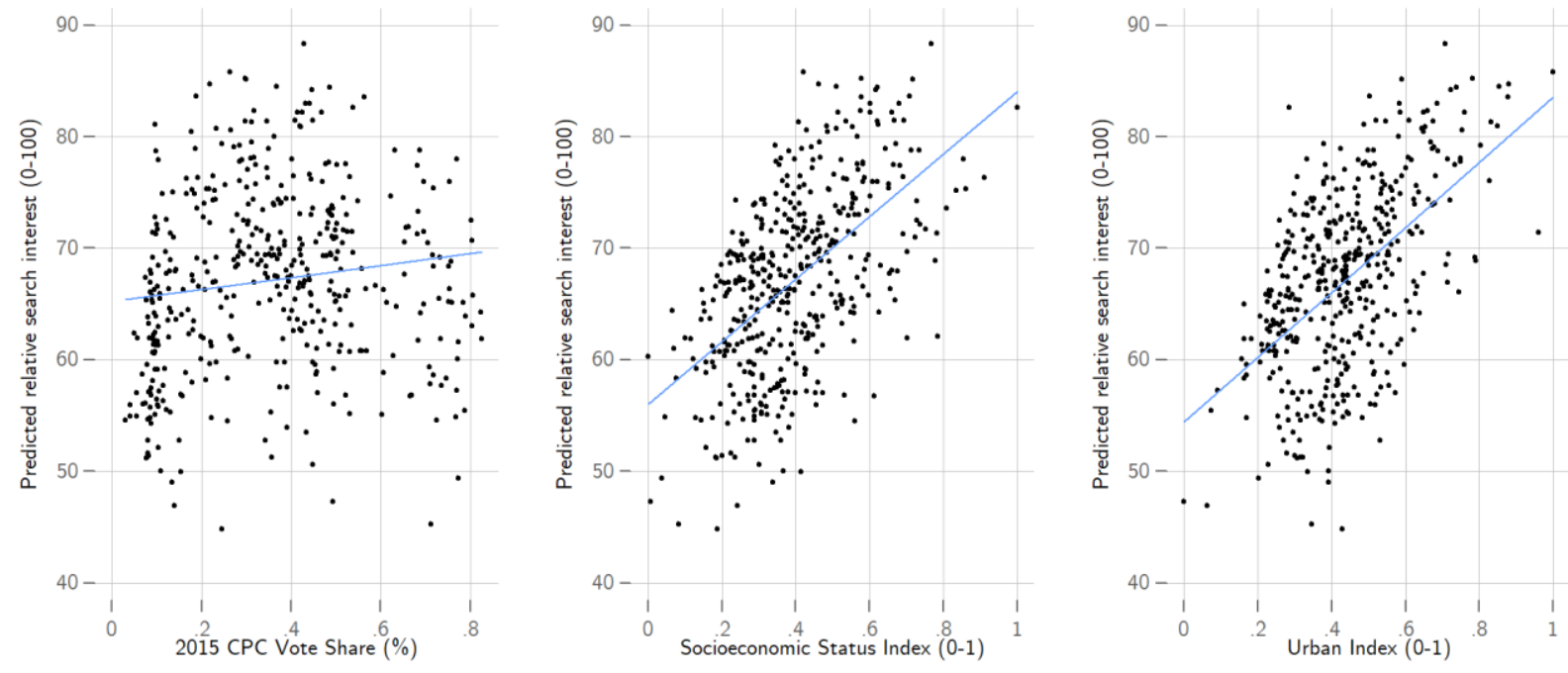

Figure 2. Predicted municipal-level search interest in coronavirus over Conservative Party vote share (left), socioeconomic status index (centre), and urban index (right).

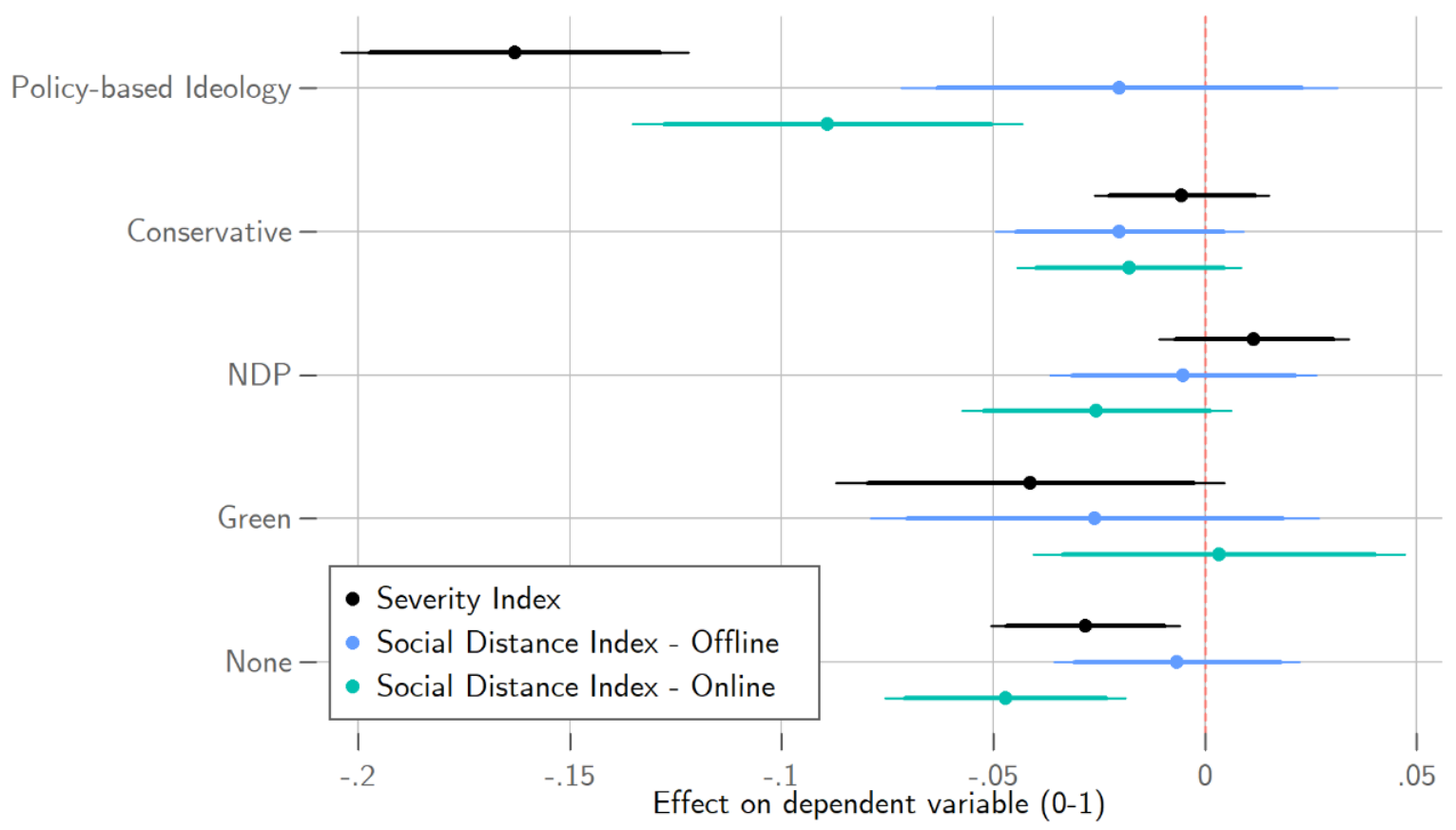

Figure 3. Effects of ideology and partisanship on severity and social distance indices. Note: 95 and 90 per cent confidence intervals. Liberal partisans are reference category for partisanship. Controls for income, education, age, religiosity, gender, language, and region. 


\section{Aggregate-level Analyses}

This elite consensus on the seriousness of COVID-19 is reflected in aggregate-level partisan differences in search traffic on the coronavirus. The estimates from our model are provided in Table A2. We plot our model predictions for Canadian municipalities below in Figure 2 across Conservative Party vote share (left panel), and our urban (centre panel) and socioeconomic status indices (right panel). There is no significant association between Conservative Party vote share and search interest in the coronavirus. Interest in the coronavirus among municipalities is much more strongly determined by socioeconomic $(p<0.001)$ and urban characteristics $(p<0.001)$.

$\underline{\text { Individual-level Analyses }}$

The null result highlighted by our aggregate-level analyses are also reflected in individual-level public sentiment towards COVID-19 and self-reported social distancing practices. Partisans of the Liberals, Conservatives, or the NDP are not significantly different in their social distancing practices or in their perceptions of COVID-19 severity after accounting for ideology and demographics, though non-partisans do generally score lower. Our model estimates for partisanship and ideology are plotted in Figure 3 and the full model estimates can be found in Table A2.

Ideology does appear to matter. Crossing the full range of this index is expected to reduce one's perceptions of COVID-19 severity by 0.2 points $(p<0.01)$. Someone who is consistently left-wing is expected to score 0.87 on the $0-1$ scale, compared to 0.71 for those who are consistently right-wing in their beliefs. Likewise, online social distancing is expected to decrease from 0.41 to 0.31 ( $\mathrm{p}<0.01)$, on the $0-1$ scale, though there appears to be no effect on offline social distancing. Ideology, rather than partisan identity or elite cue-taking, appear to be driving small partisan differences in COVID19 attitudes and social distancing practices.

\section{Discussion}

The above findings suggest that both Canadian elites and the mass public are in a moment of cross-partisan consensus on COVID-19. MPs of all parties have increasingly emphasized the crisis and reinforced the messages of mainstream expert communities. At the aggregate level, there is no evidence of a relationship between the partisan leanings of municipalities and interest in the coronavirus, and at the individual-level very small partisan differences generally disappear when controlling for ideology and demographics. Unlike in the United States, response to the coronavirus is not structured by partisanship, at least at the moment. As the crisis wears on and economic costs mount, it is essential that Canadian parties maintain a united front to avoid eroding this unique moment of societal consensus.

\section{References}

Bakker, Bert, Yphtach Lelkes and Ariel Malka. 2019. "Understanding Partisan Cue Receptivity: Tests of Predictions from the Bounded Rationality and Expressive Utility Perspectives.” Journal of Politics. Advanced Online Publication. 
Berinsky. Adam J. 2009. In Time of War: Understanding American Public Opinion from World War II to Iraq. Chicago, IL: University of Chicago Press.

Bischof, Daniel and Markus Wagner. 2019. "Do Voters Polarize When Extreme Parties Enter Parliament?” American Journal of Political Science 63 (4): 888-904.

Carmichael, Jason T. and Robert J. Brulle. 2017. "Elite Cues, Media Coverage, and Public Concern: An Integrated Path Analysis of Public Opinion on Climate Change, 2001-2013.” Environmental Politics 26: 232-52.

Cochrane, Christopher. 2015. Left and Right: The Small World of Political Ideas. Montreal-Kingston: McGill-Queen's University Press.

Cornelson, Kirsten and Boriana Miloucheva, B. 2020. "Political Polarization, Social Fragmentation, and Cooperation During a Pandemic." Available at:

https://www.economics.utoronto.ca/index.php/index/research/workingPaperDetails/663

Kushner Gadarian, Shana, Sara Wallace Goodman and Thomas B. Pepinsky. 2020. "Partisanship, Health Behavior, and Policy Attitudes in the Early Stages of the COVID-19 Pandemic." Available at SSRN: https://ssrn.com/abstract $=3562796$

Lenz, Gabriel S. 2012. Follow the Leader? How Voters Respond to Politicians' Policies and Performance. Chicago, IL: University of Chicago Press.

Merkley, Eric and Dominik A. Stecula. In press. "Party Cues in the News: Democratic Elites, Republican Backlash, and the Dynamics of Climate Skepticism." British Journal of Political Science. Available at: https://osf.io/azrxm/

Merolla, Jennifer L., Laura B. Stephenson and Elizabeth J. Zechmeister. 2016. "Deciding Correctly: Variance in the Effective Use of Party Cues." In Voting Experiments, ed. André Blais, JeanFrançois Laslier and Karine Van der Straeten. Heidelberg, Germany: Springer International Publishing.

Mondak, Jeffrey J. 1993. "Public Opinion and Heuristic Processing of Source Cues." Political Behavior 15 (2): 167-92.

Tesler, Michael. 2018. "Elite Domination of Public Doubts about Climate Change (Not Evolution)." Political Communication 35 (2): 306-26.

Zaller, John. 1992. The Nature and Origins of Mass Opinion. New York: Cambridge University Press. 


\section{Appendix}

Table A1. Factor loadings

\begin{tabular}{lccc}
\hline Variable & Factor 1 & Factor 2 & Uniqueness \\
\hline Worked from home & -0.164 & 0.733 & 0.437 \\
Avoided bars, restaurants, and crowds & 0.767 & -0.001 & 0.412 \\
Avoided grocery stores at peak times & 0.601 & 0.210 & 0.595 \\
Avoided in-person contact & 0.707 & 0.068 & 0.495 \\
Stocked up on provisions & 0.258 & 0.404 & 0.770 \\
Kept distance of two metres & 0.767 & -0.001 & 0.412 \\
Switched to virtual meetings & 0.266 & 0.662 & 0.492 \\
Switched to online shopping & 0.238 & 0.614 & 0.566 \\
Avoided domestic travel & 0.715 & 0.158 & 0.465 \\
Avoided public transit & 0.705 & 0.187 & 0.468 \\
\hline
\end{tabular}

Note: We generate two scales of social distancing: Offline and Online. Offline consists of avoiding bars, restaurants, and crowds; avoiding grocery stores at peak times; avoiding in-person contact; keep a distance of two metres; avoiding domestic travel; and avoiding public transit. Online consists of working from home, switching to virtual meetings; and switching to online shopping. 
Table A2. Regression estimates, OLS

\begin{tabular}{|c|c|c|c|c|c|c|c|c|}
\hline & \multirow{2}{*}{\multicolumn{2}{|c|}{ Aggregate }} & \multicolumn{6}{|c|}{ Individual-level } \\
\hline & & & \multicolumn{2}{|c|}{ Severity } & \multicolumn{2}{|c|}{ Offline SD } & \multicolumn{2}{|c|}{ Online SD } \\
\hline & Coef. & $\mathrm{SE}$ & Coef. & SE & Coef. & SE & Coef. & SE \\
\hline CPC Vote Share & -5.88 & 8.24 & & & & & & \\
\hline SES & $29.32^{* * *}$ & 5.35 & & & & & & \\
\hline Urban & $22.72 * * *$ & 7.19 & & & & & & \\
\hline Ideology & & & $-0.02 * * *$ & 0.00 & 0.00 & 0.00 & $-0.01 * * *$ & 0.00 \\
\hline Conservative PID & & & -0.01 & 0.01 & -0.02 & 0.01 & -0.02 & 0.01 \\
\hline NDP PID & & & 0.01 & 0.01 & -0.01 & 0.02 & -0.03 & 0.02 \\
\hline Green PID & & & $-0.04^{*}$ & 0.02 & -0.03 & 0.03 & 0.00 & 0.02 \\
\hline Other PID & & & -0.02 & 0.02 & 0.03 & 0.03 & -0.01 & 0.03 \\
\hline No PID & & & $-0.03 * *$ & 0.01 & -0.01 & 0.01 & $-0.05^{* * *}$ & 0.01 \\
\hline Income & & & $0.01 * *$ & 0.00 & $-0.01 * * *$ & 0.00 & $0.02 * * *$ & 0.00 \\
\hline Education & & & $-0.00^{*}$ & 0.00 & $0.02^{* * *}$ & 0.00 & $0.02 * * *$ & 0.00 \\
\hline Age & & & $0.00 * * *$ & 0.00 & $0.01 * * *$ & 0.00 & $-0.00 * * *$ & 0.00 \\
\hline Religiosity & & & $0.02 * * *$ & 0.00 & $-0.02 * * *$ & 0.00 & 0.01 & 0.00 \\
\hline Urban & & & 0.00 & 0.00 & $-0.01 * * *$ & 0.00 & $0.01 *$ & 0.00 \\
\hline Female & & & 0.00 & 0.01 & $0.10^{* * *}$ & 0.01 & $0.02 * *$ & 0.01 \\
\hline French & & & $-0.08 * * *$ & 0.02 & $-0.09 * * *$ & 0.03 & $0.05^{*}$ & 0.03 \\
\hline Constant & $31.02^{* * *}$ & & $0.84^{* * *}$ & 0.03 & $0.49 * * *$ & 0.05 & $0.23 * * *$ & 0.04 \\
\hline Fixed effects & Provinc & & Regic & & Regic & & Regi & \\
\hline $\mathrm{R}^{2}$ & 0.60 & & 0.12 & & 0.18 & & 0.1 & \\
\hline $\mathrm{N}$ & 87 & & 225 & & 225 & & 225 & \\
\hline
\end{tabular}

Note: ${ }^{*} \mathrm{p}<0.1,{ }^{* *} \mathrm{p}<0.05,{ }^{* * *} \mathrm{p}<0.01 . \mathrm{SD}=$ social distancing; robust standard errors for aggregate-level model. 